\title{
Prepared responses and gastric lesions in rats
}

\author{
MICHAEL N. GUILE and N. BRUCE McCUTCHEON \\ State University of New York at Albany, Albany, New York 12222
}

\begin{abstract}
The importance of prepared responses (Seligman \& Hager, 1972) in the induction of stomach lesions by tailshock restraint in rats was examined in two experiments. In Experiment 1, the prevention of a species-specific defense reaction by bodily restraint led to increased levels of stomach ulceration compared with controls. In Experiment 2, giving highly restrained rats the opportunity to engage in gnawing, a prepared response for the rat, resulted in a significant reduction in gastric pathology. The data were related to Weiss' two-factor model of coping behavior and ulceration.
\end{abstract}

Several studies (Bonfils, Rossi, Liefooghe, \& Lambling, 1959; Brodie \& Hanson, 1960; Buchanan \& Caul, 1974; Hanson, 1963; Mikhail \& Holland, 1966) have tried somatic restraint as a means of inducing gastric lesions in rats. As reported by Bonfils, Liefooghe, Gellé, Dubrasquet, and Lambling (1960), the rat's typical motoric reaction to restraint initially is continuous, uncontrolled agitation followed by intermittent, paroxysmal agitation. We have observed such behavior in rats subjected to a tailshock-restraint procedure (Guile \& McCutcheon, 1980; McCutcheon \& Guile, Note 1) developed for producing relatively rapid formation of gastric lesions. Struggling during restraint can be considered a "prepared" defense reaction (Bolles, 1970; Seligman, 1970; Seligman \& Hager, 1972), and blocking such a reaction should increase the aversiveness of the treatment. By increasing the degree of restraint, we would expect that the level of stress would increase and thus cause more gastric erosions. Experiment 1 examines this question by utilizing two levels of restraint in an ulcer-induction procedure developed and successfully used in our laboratory (Guile \& McCutcheon, 1980; McCutcheon \& Guile, Note 1).

\section{EXPERIMENT 1}

\section{Method}

Subjects. The animals were 22 male Long-Evans hooded rats from Blue Spruce Farms (Altmont, New York) about 3 to 4 months old.They were housed individually in a temperature- and humidity-controlled room with a 12-h/12-h light/dark cycle (lights on at $0700 \mathrm{~h}$, lights off at $1900 \mathrm{~h}$ ). The rats were maintained ad lib on tap water and Wayne Lab-Blox, with the exception that all subjects were food deprived $48 \mathrm{~h}$ prior to the erosion-induction procedure. Eleven subjects each were assigned to the two groups.

Apparatus. Greater details about both the apparatus and general procedure are available in Guile and McCutcheon (1980). Two

This research was supported by a grant from the National Institute of Arthritis, Metabolism, and Digestive Diseases. We thank Scott Nelson for help in collecting data. Send reprint requests and other inquiries to either Michael Guile or Bruce McCutcheon, Department of Psychology, SUNY at Albany, 1400 Washington Avenue, Albany, New York 12222. levels of restraint were used. The greater restraint was accomplished by an apparatus that consisted of a 14-cm-long piece of Plexiglas tubing (interior diameter $=5.1 \mathrm{~cm}$ ) with a Sears rubber mack gasket (interior diameter $=3.2 \mathrm{~cm}$ ) epoxied to the front end (to hold the rat about the neck and to prevent its shoulders from slipping out). At the other open, rear end, an assembly with dowels was placed to prevent the subject from backing out during a session.

The lesser restraint apparatus was constructed from a tube $17.5 \mathrm{~cm}$ long and was closed at one end with $1 / 4-\mathrm{in}$. $(.6-\mathrm{cm})$ hardware cloth. This apparatus encased the whole rat inside the tube and allowed some whole-body rotation and front-paw grasping movements.

Electric shocks were produced by a Lafayette Instrument Company constant current ac shocker (Model 82400) and applied through fuse-clip tail electrodes. Shock delivery was controlled by solid state and electromechanical equipment. Stomachs were scored for lesions with a Bausch and Lomb dissecting stereoscopic microscope at $15 \times$ magnification.

Procedure. Animals were assigned randomly to the two restraint groups at the time of running. They were placed in their respective restraint tubes. These two groups were then treated identically. The rats' tails were cleaned with alcohol swabs, and then shock electrodes were affixed approximately $3 \mathrm{~cm}$ away from the base of the tail (with about $4 \mathrm{~mm}$ of tail between the two electrodes) using adhesive tape. Following this, a 6-h session of constant current ac 3-mA, 1-sec unsignaled electric shocks delivered on a variable time $45-\mathrm{sec}$ schedule was begun. The subjects averaged a total of 480 such shocks over the 6-h period. All such sessions were begun between 0800 and $1100 \mathrm{~h}$ and were ended between 1400 and $1700 \mathrm{~h}$.

Immediately after the $6 \mathrm{~h}$ of unsignaled shocks, the animals were given lethal doses of sodium pentobarbital ip. Their stomachs were removed, cut open along the greater curvature, rinsed with $.9 \%$ saline, pinned flat on styrofoam blocks, and photographed on color slide film. The stomachs were scored while fresh under a dissecting microscope for number and cumulative length (the sum of the lengths of individual lesions) of discrete clotted bloodfilled glandular lesions. Statistical comparisons were made by two-tailed Mann-Whitney U tests. The scores were not corrected for ties. This assured that any significant differences were actually at a more conservative confidence level (Siegel, 1956, p. 125).

\section{Results}

Ulcer count. One hundred percent of the subjects in the greater restraint group $(11 / 11)$ showed glandular stomach lesions, while $45.5 \%(5 / 11)$ of the rats in the lesser restraint group did so. The mode, median, and mean \pm standard deviation for the high-restraint group were, respectively, 13 (three cases), 13, and 
$12.4 \pm 4.9$. The corresponding measures for the lowrestraint group were, in order, 0 (six cases), 0 , and $3.4 \pm 7.9$. This difference was significant $(U=12$, $\mathrm{p}<.002$, two-tailed).

Cumulative lesion length $(\mathrm{mm})$. The median and mean \pm SD for the high-restraint group were 9.6 and $12 \mathrm{~mm} \pm 6$, respectively, while for the low-restraint group, the same measures were 0 and $2.2 \mathrm{~mm} \pm 5.7$. This difference was significant $(U=11, p<.002$, two-tailed).

\section{Discussion}

Although both groups received the same shock treatment, the group subjected to less restraint had significantly less gastric pathology than did the group with greater restraint. This difference must be attributed to the difference in terms of restraint. Although the subjects in the lesser restraint group could not reach their hindquarters, their upper bodies were relatively free. With their front paws, they could grasp the hardware cloth mesh or touch their heads. They could move around somewhat within the tube and they struggled vigorously, especially after shock delivery (which we observed them to do often). Animals in the high-restraint condition were more restricted. Their front legs were folded under their bodies, and their heads stuck out of the tube so they could not touch them. Being held by the neck in a shorter tube, there was little they could do but flinch and vocalize to shock deliveries. They could not struggle nearly as much as the low-restraint group. Experiment 2 extends the investigation of the highrestraint group by giving two groups of neck-restraint subjects differential access to wood for gnawing.

\section{EXPERIMENT 2}

Weiss, Pohorecky, Salman, and Gruenthal (1976) showed that paired rats that could fight each other in response to shock had reduced gastric lesions compared with animals that received the same shock but that were shocked alone. We were interested to see if simply providing an inanimate object to chew during restraint would reduce stress-produced lesions. Our reasoning was that providing rats an opportunity to engage in a prepared defense or escape reaction would counteract the stress of being restrained and thus reduce gastric lesions. Gnawing is a renowned behavior of feral rats (Barnett, 1975, p .56; Canby, 1977) that is clearly of service in escape reactions (Keeler, 1946)-one of the reasons why laboratory rats are not housed in wooden cages. Laboratory rats will readily gnaw wood placed in their home cages (Cooper \& Trowill, 1974; Keeler, 1946; Guile $\&$ McCutcheon, Note 2). We gave one of two highly restrained groups of rats the opportunity to chew a block of wood.

\section{Method}

Subjects. The subjects were 18 rats similar to those of Experiment 1 . Their pretreatment was identical to that of Experiment 1.

Apparatus. The high-restraint neck tubes from Experiment 1 were used with one modification for the gnaw group. A $2.5 \times 4$ $\times 8 \mathrm{~cm}$ piece of pine wood was fixed at mouth level (long side perpendicular to the tube) about $5 \mathrm{~cm}$ from the front of the restraint tube within easy reach of gnaw-condition subjects. Pine is a wood moderately well preferred by rats for home-cage gnawing (Cooper \& Trowill, 1974). The rest of the apparatus was the same as in Experiment 1.

Procedure. Animals were assigned randomly to the gnaw $(n=9)$ and no-gnaw $(n=9)$ conditions at the time of test. The placing of rats in the restraint tubes, the electric shock values and schedule, sacrificing, scoring, and statistical procedures were the same as in Experiment 1 .

\section{Results}

Wood gnawing. All gnaw-group subjects chewed wood, on the order of .5 to $2 \mathrm{~g}$ over $6 \mathrm{~h}$. Animals rarely gnawed wood in response to shock but generally did so in between shocks. Upon examination, wood chips were absent from the gastrointestinal tracts of the rats in the gnaw group.

Ulcer count. In the no-gnaw group, $100 \%(9 / 9)$ of the subjects had glandular stomach lesions, and $66.7 \%(6 / 9)$ of the subjects in the gnaw group had stomach lesions. The median and mean \pm SD for the no-gnaw group were 11 and $13.8 \pm 9.4$, respectively, while the same measures for the gnaw group were 1 and $6 \pm 7.9$. This difference was significant $(U=17$, $\mathrm{p}<.05$, two-tailed).

Cumulative lesion length $(\mathrm{mm})$. The median and mean \pm SD of cumulative lesion length for no-gnaw subjects were 10.7 and $9.4 \mathrm{~mm} \pm 7.2$. The same measures for the gnaw group were .4 and $3.7 \mathrm{~mm}$ \pm 5.1 . This difference was significant $(U=17, p<.05$, two-tailed).

\section{Discussion}

Giving rats an opportunity to gnaw, a prepared response (Seligman, 1970; Seligman \& Hager, 1972), reduced gastric erosions. ${ }^{1}$ Our results in combination with those of Weiss et al. (1976) suggest that the important stress-reducing factor is the opportunity to engage in a defense or escape response rather than fighting with another animal. Weiss et al. (1976, p. 258) recognized this possibility when they suggested that shock-driven fighting was just one example of "certain highly pre-potent responses in danger situations."

\section{GENERAL DISCUSSION}

Experiment 1 showed that prevention of a speciesspecific defense reaction (Bolles, 1970) results in increased glandular stomach lesions. In Experiment 2, allowing rats the opportunity to engage in a prepared escape response (Seligman, 1970; Seligman \& Hager, 1972) alleviated ulceration. The data are supportive 
in a very general way of Weiss' (Weiss, 1971a, 1972, 1977; Weiss et al., 1976) two-factor model of the relationship between coping behavior and ulceration. However, this support may be by virtue of Weiss' broad definitions. The two factors in the theory are the number of responses emitted in the stressful situation and the amount of relevant feedback that these responses immediately provide. Relevant feedback is defined as stimuli not associated with a stressor that follow the response (Weiss, 1971a, p. 10). These stimuli act to alleviate stress. The amount of stomach ulceration is inversely proportionate to the amount of relevant feedback produced by coping responses. A subject that has a coping response available that brings about relevant feedback (e.g., the termination of shock) will display less gastric pathology than a subject that does not have such a response opportunity but who receives the same amount of shock (Moot, Cebulla, \& Crabtree, 1970; Tsuda \& Hirai, 1975; Weiss, 1968, 1971a, 1971b). Reducing the amount of relevant feedback derived from coping, or even making the stimuli negative (e.g., punishing the coping response), will result in more severe levels of ulceration (Weiss, 1971c). Weiss et al. (1976, pp. 258259) have suggested that prepared responses may inherently produce their own relevant feedback. This might apply to struggling and gnawing. However, it might be more parsimonious to attribute their ulcerreducing value to response-produced distraction from the discomfort of the ulcerogenic procedure. Alternatively, prohibiting defense/escape responses may exacerbate the fearfulness of the situation, thus elevating the level of stress.

\section{REFERENCE NOTES}

1. McCutcheon, N. B., \& Guile, M. N. ESB reduction of shockrestraint induced gastric lesions in rats. Paper presented at the meeting of the Eastern Psychological Association, Hartford, Connecticut, April 1980.

2. Guile, M. N., \& McCutcheon, N. B. Unpublished observations, 1978.

\section{REFERENCES}

Barnett, S. A. The rat (Rev. ed.). Chicago: University of Chicago Press, 1975.

Bolles, R. C. Species-specific defense reactions and avoidance learning. Psychological Review, 1970, 77, 32-48.

Bonfils, S., Liefooghe, G., Gellé, X., Dubrasquet, M., \& Lambling, A. "Ulcère" expérimental de contrainte du rat blanc III. Revue Française d'Etudes Cliniques et Biologiques, 1960, 5, 571-581.

Bonfils, S., Rossi, G., Liefooghe, G., \& Lambling, A. "Ulcère expérimental de contrainte du rat blanc I. Revue Française d'Etudes Clinique et Biologiques, 1959, 4, 146-150.
Brodie, D. A., \& Hanson, H. M. A study of the factors involved in the production of gastric ulcers by the restraint technique. Gastroenterology, 1960, 38, 353-360.

Buchanan, D. C., \& Caul, W. F. Gastric ulceration in rats induced by self-imposed immobilization or physical restraint. Physiology \& Behavior, 1974, 13, 583-588.

Canby, T. Y. The rat. National Geographic, 1977, 152, 60-87. Cooper, P. H., \& Trowill, J. A. Wood gnawing preferences in rats. Physiology \& Behavior, 1974, 13, 845-847.

Guile, M. N., \& McCutcheon, N. B. A tailshock-restraint technique for acute induction of gastric lesions in rats. Behavior Research Methods \& Instrumentation, 1980, 12, 359-360.

Hanson, H. M. Restraint and gastric ulcers. Journal of Neuropsychiatry, 1963, 4, 390-395.

KeEle R, C. E. Note on gnawing in the gray Norway rat and its coat-character derivative strains. Journal of Comparative and Physiological Psychology, 1946, 39, 241-242.

Mikhail, A. A., \& Holland, H. C. A simplified method of inducing stomach ulcers. Journal of Psychosomatic Research, 1966, 9, 343-347.

Moot, S. A., Ce bulla, R. P., \& Crabtree, J. M. Instrumental control and ulceration in rats. Journal of Comparative and Physiological Psychology, 1970, 71, 405-410.

Seligman, M. E. P. On the generality of the laws of learning. Psychological Review, 1970, 77, 406-418.

Seligman, M. E. P., \& Hager, J. L. (Eds.). Biological boundaries of learning. New York: Appleton-Century-Crofts, 1972.

Siegel, S. Nonparametric statistics. New York: McGraw-Hill, 1956.

Tsuda, A., \& Hirai, H. Effects of the amount of required coping response tasks on gastrointestinal lesions in rats. Japanese Psychological Research, 1975, 17, 119-132.

WEISS, J. M. Effects of coping responses on stress. Journal of Comparative and Physiological Psychology, 1968, 65, 251-260.

WEISS, J. M. Effects of coping behavior in different warning signal conditions on stress pathology in rats. Journal of Comparative and Physiological Psychology, 1971, 77, 1-13. (a)

WEISS, J. M. Effects of coping behavior with and without a feedback signal on stress pathology in rats. Journal of Comparative and Physiological Psychology, 1971, 77, 22-30. (b)

WEISS, J. M. Effects of punishing the coping response (conflict) on stress pathology in rats. Journal of Comparative and Physiological Psychology, 1971, 77, 14-21. (c)

WeISS, J. M. Psychological factors in stress and disease. Scientific American, 1972, 226(6), 104-113.

WEISS, J. M. Psychological and behavioral influences on gastrointestinal lesions in animal models. In J. D. Maser \& M. E. P. Seligman (Eds.), Psychopathology: Experimental models. San Francisco: Freeman, 1977.

Weiss, J. M., Pohorecky, L. A., Salman, S., \& Gruenthal, M. Attenuation of gastric lesions by psychological aspects of aggression in rats. Journal of Comparative and Physiological Psychology, 1976, 90, 252-259.

\section{NOTE}

1. The effect is not due merely to the placing of an object in front of the animals' faces. Rats presented with nongnawable stainless steel rods do not show a reduction in stomach pathology (Guile \& McCutcheon, Note 2).

(Received for publication March 12, 1980; revision accepted May 2, 1980.) 